\title{
Mathematical modeling based evaluation and simulation of boron removal in bioelectrochemical systems
}

\author{
Qingyun Ping ${ }^{\mathrm{a}}$, Ibrahim M. Abu-Reesh ${ }^{\mathrm{b}}$, Zhen $\mathrm{He}^{\mathrm{a}, *}$ \\ a Department of Civil and Environmental Engineering, Virginia Polytechnic Institute and State University, Blacksburg, VA 24061, USA \\ b Department of Chemical Engineering, College of Engineering, Qatar University, P.O. Box 2713, Doha, Qatar
}

\section{H I G H L I G H T S}

- Mathematical models are developed to understand boron removal in BES.

- Boron removal can be driven by electromigration induced by current generation.

- Diffusion induced by a salt concentration gradient also contributes to boron removal.

- Osmosis and current driven convection transport play diverse roles in different BES.

\section{G R A P H I C A L A B S T R A C T}

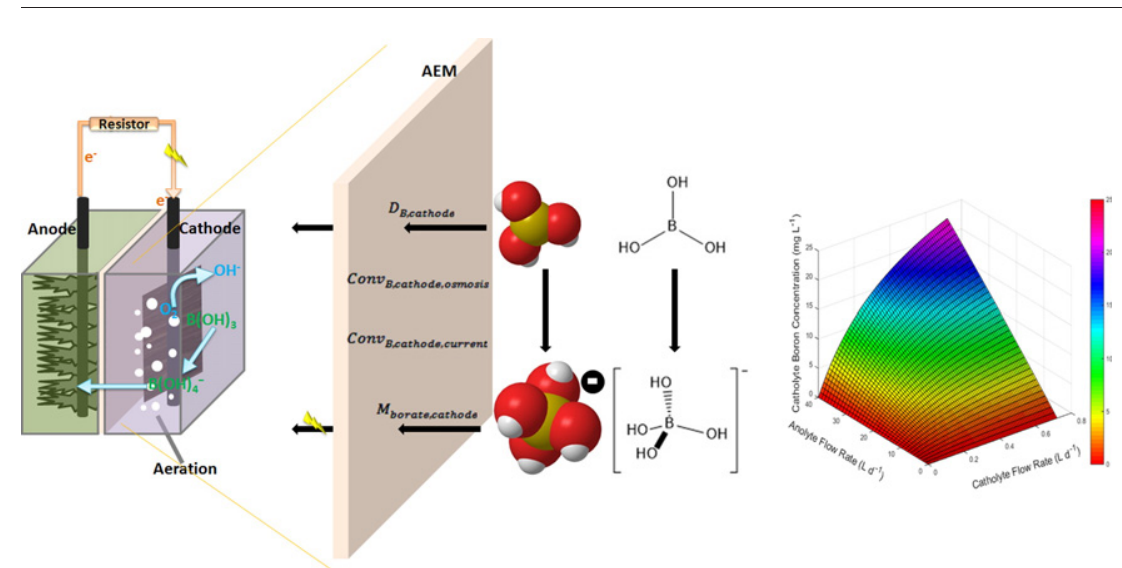

\begin{abstract}
A B S T R A C T
Boron removal is an arising issue in desalination plants due to boron's toxicity. As an emerging treatment concept, bioelectrochemical systems (BES) can achieve potentially cost-effective boron removal by taking advantage of cathodic-produced alkali. Prior studies have demonstrated successful removal of boron in microbial desalination cells (MDCs) and microbial fuel cells (MFCs), both of which are representative BES. Herein, mathematical models were developed to further evaluate boron removal by different BES and understand the key operating factors. The models delivered very good prediction of the boron concentration in the MDC integrated with Donnan Dialysis (DD) system with the lowest relative root-mean-square error (RMSE) of $0.00 \%$; the predication of the MFC performance generated the highest RMSE of 18.55\%. The model results of salt concentration, solution $\mathrm{pH}$, and current generation were well fitted with experimental data for RMSE values mostly below $10 \%$. The long term simulation of the MDC-DD system suggests that the accumulation of salt in the catholyte/stripping solution could have a positive impact on the removal of boron due to osmosis-driven convection. The current generation in the MDC may have little influence on the boron removal, while in the MFC the current-driven electromigration can contribute up to $40 \%$ of boron removal. Osmosis-induced convection transport of boron could be the major
\end{abstract}

Keywords:

Boron removal

Bioelectrochemical systems

Microbial fuel cells

Microbial desalination cells

Mathematical modeling

Water treatment

\footnotetext{
Abbreviations: BES, Bioelectrochemical systems; MDC, Microbial desalination cell; MFC, Microbial fuel cell; DD, Donnan dialysis; AEM, Anion exchange membrane; CEM, Cation exchange membrane; RMSE, Root mean square error.

* Corresponding author.

E-mail address: zhenhe@vt.edu (Z. He).
} 
driving force for boron removal to a low level $<2 \mathrm{mg} \mathrm{L}^{-1}$. The ratio between the anolyte and the catholyte flow rates should be kept $>22.2$ in order to avoid boron accumulation in the anolyte effluent.

(C) 2016 Elsevier B.V. All rights reserved.

\section{Introduction}

With the global population growth, the issue of limited access for clean and safe freshwater has resulted in increasing attention on desalination of seawater or brackish water as an alternative source of freshwater. Despite the high energy cost, the installed desalination capacity worldwide has reached 74.8 million $\mathrm{m}^{3} \mathrm{~d}^{-1}$ (in 2012) and continues to increase (Bennett, 2013). Reverse osmosis (RO) is used as the desalination technology in 63\% of the current desalination industry (Gude, 2016). Although conventional RO technologies can achieve almost $100 \%$ rejection of salt, the rejection of boron by RO is low at $40-70 \%$ and often requires post-treatment (Guler et al., 2010; USBR, 2003).

The removal of boron is essential due to its toxic effects on plants, animals, and human beings (Guler et al., 2015). The World Health Organization (WHO) recommends the boron limit in drinking water to be as low as $2.4 \mathrm{mg} \mathrm{L}^{-1}$ (Kabay and Bryjak, 2015), while seawater contains $\sim 5 \mathrm{mg} \mathrm{L}^{-1}$ and brackish water has up to $40 \mathrm{mg} \mathrm{L}^{-1}$ of boron. The common form of boron in natural water is non-dissociable boric acid, which is non-charged and very small in size (Melnik et al., 1999). It is critical to raise $\mathrm{pH}$ above $\mathrm{pKa}$ value of 9.14 in order to improve rejection of boron in RO; in that way, boron transforms to borate ions with larger hydrated radius and negative charge (Eq. (1)) (Kabay and Bryjak, 2015; Guler et al., 2009). However, the alkalization process will increase the consumption of chemicals such as sodium hydroxide, and result in higher cost of desalinated water (Guler et al., 2015).

$\mathrm{B}(\mathrm{OH})_{3}+\mathrm{H}_{2} \mathrm{O} \Leftrightarrow \mathrm{B}(\mathrm{OH})_{4}^{-}+\mathrm{H}^{+}$.

Bioelectrochemical systems (BES) are an emerging technology that takes advantage of microbial interaction with solid electron acceptors/ donors (Wang and Ren, 2013). As a representative BES, microbial fuel cells (MFCs) can transform chemical energy stored in waste into electrical energy with the benefit of removing the intrinsic organics in wastewater (Li et al., 2014; Venkidusamy et al., 2016). The concept of BES is also applied to desalination of seawater or brackish water in microbial desalination cell (MDCs) driven by in-situ electricity production (Cao et al., 2009; Sevda et al., 2015). With electrons released from the oxidation of organic matters in an anode, the reduction of a terminal electron acceptor such as oxygen in a cathode is driven to produce hydroxide ions (Eq. (2)) (Popat et al., 2012). This special feature has been employed to accomplish boron removal with the transformation of boric acid to borate ions in BES, and both the MDC-Donnan Dialysis (DD) coupled system and an MFC have been demonstrated to achieve effective boron removal (Ping et al., 2015a, 2016). Although the application of BES in boron removal is promising, the mechanism of boron transport is not fully understood and this could mislead the operational strategies. For example, the loss of high-mobility hydroxide ions in the desalination compartment of an MDC can lead to reduced alkalinity, which challenges the stability of borate ion electromigration. In particular, it is important to further understand the transport of boron in solution with neutral $\mathrm{pH}$ and evaluate the contribution of different driving forces.

$\mathrm{O}_{2}+2 \mathrm{H}_{2} \mathrm{O}+4 \mathrm{e}^{-} \rightarrow 4 \mathrm{OH}^{-}$.

Mathematical modeling can provide useful insight into the boron transport processes in BES. Owing to the multiple processes of microbiology, chemistry and electrochemistry, the parameters in BES are dynamically linked (Luo et al., 2016), and most BES models that focused on the fate of solute did not deal with non-dissociable compounds (Harnisch et al., 2009; Picioreanu et al., 2010; Ping et al., 2015b). Therefore, it is essential to develop BES models for evaluation of the boron removal process and prediction of the performance affected by operational factors. Herein, mathematical models were developed based on our previous BES models and the experimental data from the MDC-DD and MFC systems (Ping et al., 2015a, 2016). The models focused on the factors that could contribute to boron transformation and transport, such as $\mathrm{pH}$ change, diffusion, electromigration, ion-exchange and convective transport. The results were expected to help design suitable BES configuration and optimize operation for boron removal.

\section{Methods}

\subsection{Bioelectrochemical systems}

The mathematical models developed in this study were based on the experimental data of two BES systems from our previous studies, the MDC-DD system and the MFC system (Ping et al., 2015a, 2016). The MDC-DD system recycles the alkaline catholyte from the MDC to the stripping side of the DD, and treats the boron-containing salt solution at the feed side of the DD that acts as the pretreatment (or post-treatment) before (or after) it is desalinated in the desalination compartment of the MDC. In the DD pretreatment, the salt solution at the feed side is alkalized without salinity increase, owing to the exchange of hydroxide ions in the stripping solution with anions in the feed solution across the anion exchange membrane (AEM) in the DD. The alkalized solution with boric acid transformed into borate ions is then treated in the desalination compartment of the MDC (Fig. 1A) (Ping et al., 2015a). In the DD post-treatment system, the transported hydroxide ions from the stripping solution to the feed solution are trapped which allow boron to remain borate ions to be transferred out of the feed solution through AEM to balance the charge. Since the feed solution is pre-desalinated in MDC, the concentrations of other anions (eg. $\mathrm{Cl}^{-}$) are very low and have little competition to cross AEM (Fig. 1B) (Ping et al., 2015a). The MFC cathodic treatment of the boron-containing salt solution effectively raises the $\mathrm{pH}$ and transports borate ions (transformed from boric acid) out of the salt solution (catholyte) through the AEM (Fig. 1C) (Ping et al., 2016).

\subsection{Numerical methods and calculations}

An integrated macro-scale time-dependent model was implemented in a combination of MATLAB code (2014b, The Mathworks Inc., Natick, MA) for solving stiff differential equations (ODE 23tb). The MATLAB code defines (1) model input parameters; (2) initial biomass concentrations, substrate concentrations, salt concentrations, hydroxide concentrations and boron concentrations in the system; and (3) ODE system of mass balances. Parameter estimation was carried out by minimizing the objective function defined as relative root-mean-square error (RMSE).

RMSE $=\frac{\sqrt{\frac{\sum_{i=1}^{N}\left(y_{i}-y_{i}\right)^{2}}{N}}}{\max (y)}$

where $N$ is the total sampling time point in the simulation; $\hat{y}_{i}$ and $y_{i}$ represent experimental data and model predicted values at $t_{i}$, 

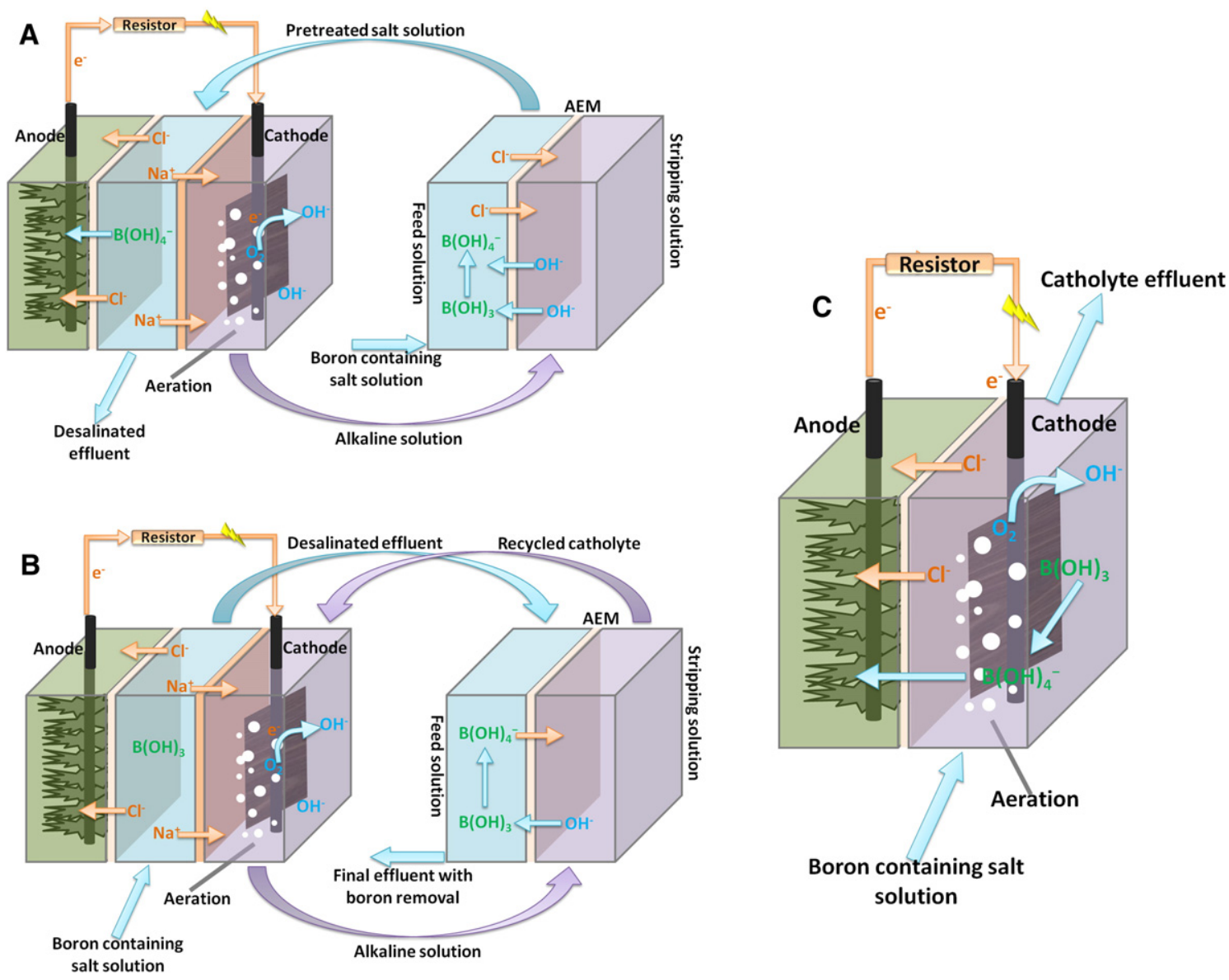

Fig. 1. The schematic illustration of BES treating boron containing salt solution: (A) MDC with DD-pretreatment; (B) MDC with DD-post-treatment; and (C) MFC cathodic treatment.

respectively. The maximum values of the experimental data were used to normalize the error in Eq. (3). To equalize the number of sampling time points in the experimental and simulation data, interpolation of both data sources was applied using "spline", which is a cubic interpolation of the values at neighboring grid points. The RMSE calculation of boron concentration used rounded values of the simulation data in accordance to the experimental measurement limitation where only integer values can be obtained. FMINCON subroutine of the MATLAB Optimization Toolbox was used to solve the optimization problem with several parameters starting at an initial estimate.

\subsection{Model formulation}

\subsubsection{MDC-DD system}

The MDC model was developed for three continuous operation modes, direct cathodic alkalization, DD as pretreatment, and DD as post-treatment for brackish water desalination and boron removal. The mass balances for substrates, microorganisms, and electron mediators in the MDC were adopted from a previous study based on the multiplicative Monod kinetics (Ping et al., 2014). The current generation was calculated by the cell voltage divided by the sum of internal resistance and external resistance. The cell voltage was calculated as the experimentally measured open circuit voltage $(\sim 0.8 \mathrm{~V})$ subtracting concentration overpotential (Ping et al., 2014). The membrane and electrolyte resistance that can contribute to the internal resistance of BES was calculated according to a previous study (Qin et al., 2015). The electrolytes in the BES were assumed to be completely mixed so that the concentrations of all soluble chemical and microbial species are uniform in each compartment. In the MDC, the mass balance of salt is governed by diffusion and electromigration that was adopted from the previous model (Ping et al., 2014). The mass balance of salt in the DD is governed by diffusion and reflected by the following equations:

$\frac{d C_{\text {salt.feed }}}{d t}=D_{\text {feed }} \cdot\left(C_{\text {salt.feed,in }}-C_{\text {salt.feed }}\right)-D_{\text {salt }, \text { feed }}$

$\frac{d C_{\text {salt,strip }}}{d t}=D_{\text {strip }} \cdot\left(C_{\text {salt,strip,in }}-C_{\text {salt,strip }}\right)-D_{\text {salt,strip }}$

where $D_{x}$ is the dilution rate $\left(\right.$ day $^{-1}$ ) defined by the flow rate $\left(\mathrm{L} \mathrm{day}^{-1}\right.$ ) divided by the volume of the compartment $x(\mathrm{~L}) ; C_{\text {salt }, x, i n}$ is the influent concentration ( $\mathrm{mol} \mathrm{L}^{-1}$ ) of the compartment $x$, and $C_{\text {salt } x}$ is the effluent concentration of the compartment $x\left(\mathrm{~mol} \mathrm{~L}^{-1}\right)$; and $D_{\text {salt } x}$ is the diffusion term that will be discussed in later section (Eq. (26)).

\subsubsection{MFC system}

In the MFC model, it is important to incorporate a noncompetitive inhibition term to regulate anodophilic microorganism growth, which thereby governs the response of current generation to a shock load of salt in the catholyte that can diffuse across AEM into the anolyte. Noncompetitive inhibition term was added to the microorganism kinetics that can decrease the microbial growth rate, but do not affect Ks, the half saturation constant (Grady et al., 2011). The anodophilic growth rate was modified as:

$k_{a}=k_{a, \max } \frac{S}{K_{a}+S} \frac{M_{O X}}{K_{M}+M_{O X}} \frac{K_{I}}{K_{I}+\left(C_{\text {salt,anode }}-C_{\text {salt,anode }, 0}\right)}$

where $k_{a, \max }$ is the maximum anodophilic microorganism growth rates $\left(\right.$ day $\left.^{-1}\right) ; S$ is the concentration of the substrate $\left(\mathrm{mg}_{-} \mathrm{S} \mathrm{L}^{-1}\right) ; K_{\mathrm{a}}$ and $K_{M}$ are the half-saturation concentrations for the anodophilic microorganisms ( $\mathrm{mg}^{-\mathrm{S} \mathrm{L}^{-1}}$ ) and the redox mediator ( $\mathrm{mg}-\mathrm{M} \mathrm{mg-a}^{-1}$ ), 
respectively; $M_{O X}$ is the oxidized mediator fraction per anodophilic microorganism ( $\left.\mathrm{mg}-\mathrm{M} \mathrm{mg- \textrm {a } ^ { - 1 }}\right) ; K_{I}$ is the inhibition coefficient; and $\left(C_{\text {salt, }}\right.$ anode $-C_{\text {salt, anode, } 0}$ ) is the term representing the salt concentration increase in the anolyte.

For the salt solution to be treated in the MFC cathode compartment, an ideal situation would be that anion electromigration across AEM from the catholyte to the anolyte reaches a balance with the cathodic hydroxide generation and thus the salinity remains same. However, when the balance is not achieved with strong anion migration and weak hydroxide production, positively charged cations will be forced to migrate across AEM along with negatively charged anions to reach charge balance, resulting in decreased salinity in the catholyte. It was assumed in the model that two factors contribute to the catholyte salinity variation: the difference between the generated hydroxide ions and electro-migrated anions across AEM, and the salt diffusion caused by a concentration gradient between the anode and cathode compartments. The equations showing the mass balance of salt in the catholyte and the anolyte are as following:

$$
\begin{aligned}
\frac{d C_{\text {salt,cathode }}}{d t}= & D_{\text {cathode }} \cdot\left(C_{\text {salt,cathode, in }}-C_{\text {salt,cathode }}\right) \\
& +\left(G_{\text {cathode }}-M_{\text {salt,cathode }}\right)-D_{\text {salt,cathode }} \\
\frac{d C_{\text {salt, anode }}=}{d t}= & D_{\text {anode }} \cdot\left(C_{\text {salt, anode, in }}-C_{\text {salt,anode }}\right)-\left(G_{\text {anode }}-M_{\text {salt,anode }}\right) \\
& +D_{\text {salt,anode }}
\end{aligned}
$$

where $G_{x}$ is the generation of hydroxide ions, and $M_{s a l t, x}$ is the electromigration of anions from the catholyte into the anolyte that is explained in Eqs. (24) \& (25). The difference between them contributes to the cation migration and leads to salt concentration variation. $D_{\text {salt }, x}$ is the diffusion of salt between the catholyte and anolyte caused by concentration gradient, which is explained in Eq. (26).

\subsubsection{Solute components}

In this study, we focus on two components in the solution, hydroxide ions and boron (boric acid and borate ions). In an MFC, both of hydroxide ions and boron species are subject to diffusion and electromigration (boron in the form of borate ion), while additionally boron is subject to convective transport by an electrical field (Nikonenko et al., 2010) and water osmosis (Dydo, 2012; Dydo and Turek, 2013). The current-driven electromigration is constrained by the possibility of each anion to be transported in relation to the product of ion concentration and mobility (Eq. (9)) (Ping et al., 2015b):

$\varphi_{i, x}=\frac{u_{i} \cdot C_{i, x}}{\sum u_{i} \cdot C_{i, x}}$

where $u_{i}\left(\mathrm{~m}^{2} \mathrm{~s}^{-1} \mathrm{~V}^{-1}\right)$ is the mobility of the anion $i$ in the solution. The convective drag transport of boron can be explained by the coupling effect between boric acid molecules and ions or water molecules. As the electric current expedites ions movement or the osmotic pressure promotes water molecules movement, they drag an additional amount of boric acid (Dydo and Turek, 2013).

The equations of mass balance of hydroxide ions and boron in the MFC are as following:

$$
\begin{aligned}
\frac{d C_{\mathrm{OH}, \text { cathode }}}{d t}= & D_{\text {cathode }} \cdot\left(C_{\mathrm{OH}, \text { cathode, in }}-C_{\mathrm{OH}, \text { cathode }}\right)+G_{\text {cathode }} \\
& -M_{\mathrm{OH}, \text { cathode }}-D_{\mathrm{OH}, \text { cathode }} \\
\frac{d C_{B, \text { cathode }}=}{d t}= & D_{\text {cathode }} \cdot\left(C_{B, \text { cathode }, \text { in }}-C_{B, \text { cathode }}\right)-M_{\text {borate,cathode }} \\
& -D_{B, \text { cathode }}-\operatorname{Conv}_{B, \text { cathode,current }}+\operatorname{Conv}_{B, \text { cathode,osmosis }}
\end{aligned}
$$

$$
\begin{aligned}
\frac{d C_{B, \text { anode }}}{d t}= & D_{\text {anode }} \cdot\left(C_{B, \text { anode }, \text { in }}-C_{B, \text { anode }}\right)+M_{\text {borate, anode }}-D_{B, \text { anode }} \\
& +\operatorname{Conv}_{B, \text { anode } \text { current }}-\operatorname{Conv}_{B, \text { anode, osmosis }}
\end{aligned}
$$

where $\operatorname{Conv}_{B, x, \text { current }}$ and $\operatorname{Conv}_{B, x, 0 \text { osmosis }}$ are the current-induced convection and water transport-induced convection, respectively, as explained in Eqs. (27) \& (28).

In the MDC-DD system, the mass balance of hydroxide ions in the catholyte of the MDC is not subject to electromigration (blocked by cation exchange membrane - CEM), and thus the term is eliminated. The mass balance of hydroxide ions is expressed in the following equations:

$$
\begin{aligned}
& \frac{d C_{\mathrm{OH}, \text { cathode }}}{d t}=D_{\text {cathode }} \cdot\left(C_{\mathrm{OH}, \text { cathode, in }}-C_{\mathrm{OH}, \text { cathode }}\right)+G_{\text {cathode }} \\
& -D_{\mathrm{OH}, \text { cathode }} \\
& \begin{aligned}
\frac{d C_{\mathrm{OH}, \text { salt }}}{d t}= & D_{\text {salt }} \cdot\left(C_{\mathrm{OH} \text {,salt,in }}-C_{\mathrm{OH}, \text { salt }}\right)-\varphi_{\mathrm{OH}, \text { salt }} \cdot \frac{I_{\mathrm{MDC}}}{F \cdot V_{\text {salt }}}-D_{\mathrm{OH}, \text { salt-anode }} \\
& -D_{\mathrm{OH}, \text { salt_cathode }}
\end{aligned} \\
& \frac{d C_{O H, f e e d}}{d t}=D_{\text {feed }} \cdot\left(C_{O H, f e e d, i n}-C_{\text {salt,feed }}\right)-D_{O H, f e e d}-E_{O H, f e e d} \\
& \frac{d C_{O H, \text { strip }}}{d t}=D_{\text {strip }} \cdot\left(C_{\mathrm{OH}, \text { strip,in }}-C_{\text {salt,strip }}\right)-D_{\mathrm{OH}, \text { strip }}+E_{\mathrm{OH} \text {,strip }}
\end{aligned}
$$

The mass balance of boron species is expressed as:

$$
\begin{aligned}
\frac{d C_{B, \text { salt }}}{d t}= & D_{\text {salt }} \cdot\left(C_{B, \text { salt,in }}-C_{B, \text { salt }}\right)-\varphi_{\text {Borate,salt }} \cdot \frac{I_{M D C}}{F \cdot V_{\text {salt }}}-D_{B, \text { salt-anode }} \\
& -D_{B, \text { salt-cathode }} \\
\frac{d C_{B, \text { anode }}}{d t}= & D_{\text {anode }} \cdot\left(C_{B, \text { anode in }}-C_{B, \text { anode }}\right)-\varphi_{\text {Borate,salt }} \cdot \frac{I_{M D C}}{F \cdot V_{\text {anode }}} \\
& -D_{B, \text { anode }}
\end{aligned}
$$

$\begin{aligned} \frac{d C_{B, \text { cathode }}}{d t}= & D_{\text {cathode }} \cdot\left(C_{B, \text { cathode in }}-C_{B, \text { cathode }}\right)-\varphi_{\text {Borate,salt }} \cdot \frac{I_{M D C}}{F \cdot V_{\text {cathode }}} \\ & -D_{B \text {, cathode }}\end{aligned}$

$$
\begin{aligned}
\frac{d C_{B, f e e d}}{d t}= & D_{\text {feed }} \cdot\left(C_{B, f e e d, \text { in }}-C_{B, f e e d}\right)-D_{B, f e e d}-E_{B, f e e d}+E_{B, \text { strip }} \\
& - \text { Conv }_{B, f e e d, \text { osmosis }}
\end{aligned}
$$

$$
\begin{aligned}
\frac{d C_{B, \text { strip }}}{d t}= & D_{\text {strip }} \cdot\left(C_{B, \text { strip in }}-C_{B, \text { strip }}\right)-D_{B, \text { strip }}-E_{B, \text { strip }}+E_{B, \text { feed }} \\
& + \text { Conv }_{B, \text { strip,osmosis }}
\end{aligned}
$$

where $E_{i, x}$ is the ion-exchange term in the DD limited by the lower salt concentration of either side:

$E_{i, x}=\varphi_{i, x} \cdot \frac{a_{e x} \cdot \min \left(C_{\text {salt.feed }}, C_{\text {salt }, \text { strip }}\right)}{V_{x}}$

where $a_{e x}$ is the ion-exchange coefficient $\left(\mathrm{Ld}^{-1}\right)$.

The $\mathrm{pH}$ is then calculated using the expression:

$p H=14+\log \left[\mathrm{OH}^{-}\right]$.

A constant $\mathrm{pH}$ was assumed in the anolyte of BES considering the buffer effect.

The hydroxide ion generation, migration of ions, and diffusion of ions are formulated in the following equations:

$G_{c}=\frac{I_{B E S}}{F \cdot V_{x}} \cdot a_{O H}$ 
$M_{i, x}=\varphi_{i, x} \cdot \frac{I_{B E S}}{F \cdot V_{x}} \cdot C_{s a l t, x} \cdot a_{e}$

$D_{i, x}=\frac{A_{\text {membrane }}}{V_{x}} \cdot\left(C_{i, x}-C_{i, y}\right) \cdot a_{d}$

where $I_{B E S}(\mathrm{~A})$ is the current generated by BES reactor; $F$ is the Faraday constant (A day $\mathrm{mol}^{-1}$ ); $V_{x}$ is the volume of the target compartment (L); $a_{\mathrm{OH}}$ is the hydroxide ion generation efficiency; $\varphi_{i}$ is the possibility of each anion to be transported across AEM driven by current (Eq. (12)); $a_{e}\left(\mathrm{~L} \mathrm{~mol}^{-1}\right)$ is the general anion electromigration coefficient; $A_{\text {membrane }}$ is the membrane surface area $\left(\mathrm{m}^{2}\right) ; a_{d}\left(\mathrm{~m} \mathrm{~d}^{-1}\right)$ is the diffusion coefficient; $y$ is the adjacent compartment to $x$ with the membrane separating them. $\Phi_{\text {salt } x}$ is equal to 1 in the case of $M_{\text {salt } x \text {. }}$.

The current-induced convection and water transport-induced convection are expressed in the following equations:

$\operatorname{Conv}_{B, x, \text { current }}=\frac{I_{B E S}}{F \cdot V_{x}} \cdot C_{B, \text { cathode }} \cdot a_{C}$

$\operatorname{Conv}_{B, x, \text { osmosis }}=\frac{\text { Osmosis }}{V_{x}} \cdot C_{B, 0} \cdot a_{o}$

$C_{\mathrm{B}, O}=\left\{\begin{array}{c}\mathrm{C}_{\mathrm{B}, \text { anode }} \text { if } \mathrm{C}_{\text {salt,cathode }}<\mathrm{C}_{\text {salt,anode }} \\ \mathrm{C}_{\mathrm{B}, \text { cathode }} \text { if } \mathrm{C}_{\text {salt,cathode }} \geq \mathrm{C}_{\text {salt,anode }}\end{array}\right.$ in MFC

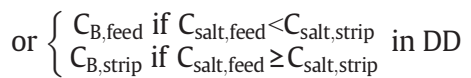

where $a_{c}\left(\mathrm{~L} \mathrm{~mol}^{-1}\right)$ is the current-induced convection coefficient, and $a_{o}\left(\mathrm{~d}^{-1}\right)$ is the osmosis-induced convection coefficient. Both convection type transports are constricted by boron concentration in the source (the compartment from which the boron transports out).
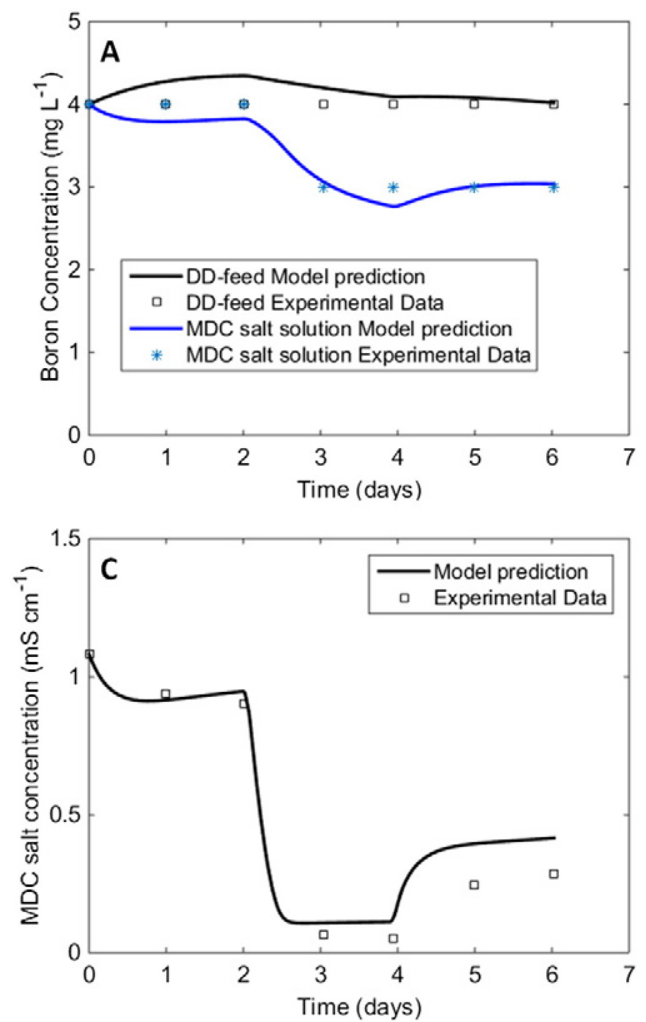

\section{Results and discussion}

\subsection{Model fitting}

\subsubsection{The MDC-DD system}

The model was fitted with the experimental conditions of varying salt solution flow rate, $0.16-0.08-0.06 \mathrm{~mL} \mathrm{~min}^{-1}$ in the MDC cathodic alkalization, $0.2-0.12-0.16 \mathrm{~mL} \mathrm{~min}^{-1}$ in the DD-pretreatment system, and $0.12-0.16 \mathrm{~mL} \mathrm{~min}^{-1}$ in the DD-post-treatment system. The parameters that were slightly adjusted during simulation included the mediator yield $(Y)$ related to current production, initial anodophilic microorganism concentration $(x a)$, and alkali production efficiency $\left(a_{\mathrm{OH}}\right)$ by the cathode; while other parameters were kept the same during all simulations. A list of the parameters is shown in Table S1 in the Supporting information. The osmosis-induced convection coefficient $a_{o}$ was estimated according to the post-DD experiments where the $\mathrm{pH}$ of the feed solution was below 9.14 and boron was in the form of noncharged boric acid and thus not subject to ion exchange ( $E_{i, x}$ in Eqs. (20) \& (21)) (Fig. S1F). Incorporating concentration-gradient-driven diffusion $\left(D_{i, x}\right)$ alone in the boron mass balance equations was not able to achieve satisfactory fitting results. Thus, the osmosis-driven con-

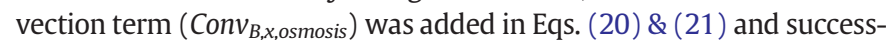
fully improved the fitting results of the DD-feed boron concentration with RMSE decreased from $42.45 \%$ (Fig. S1) to $0.00 \%$ (Fig. S2A). $u_{\text {borate }}$ and $u_{O H}$ were kept the same (5.33 and $45.7210^{-8} \mathrm{~m}^{2} \mathrm{~s}^{-1} \mathrm{~V}^{-1}$ ) under most conditions except in the MDC desalination compartment where they were multiplied with the factor $\mathrm{e}^{-300 C_{\mathrm{Cl}, \text { salt }}}$ and $15 \mathrm{e}^{-300 \mathrm{C}_{\mathrm{C}, \text { salt }}}$ considering the strong competition of anions (e.g., chloride ions). This adjustment improved the fitting of $\mathrm{pH}$ in the salt solution with RMSE decreased from $11.59 \%$ to $6.68 \%$, and the RMSE of the boron concentration fitting decreased from $50.75 \%$ to $1.44 \%$ in the MDC-DD pretreatment system (Fig. S3A \& B and Fig. 2A \& B). In the MDC cathodic alkalization system, the fitting of $\mathrm{pH}$ in the salt solution was improved with RMSE decreased from $15.79 \%$ to $8.93 \%$, and the RMSE of the
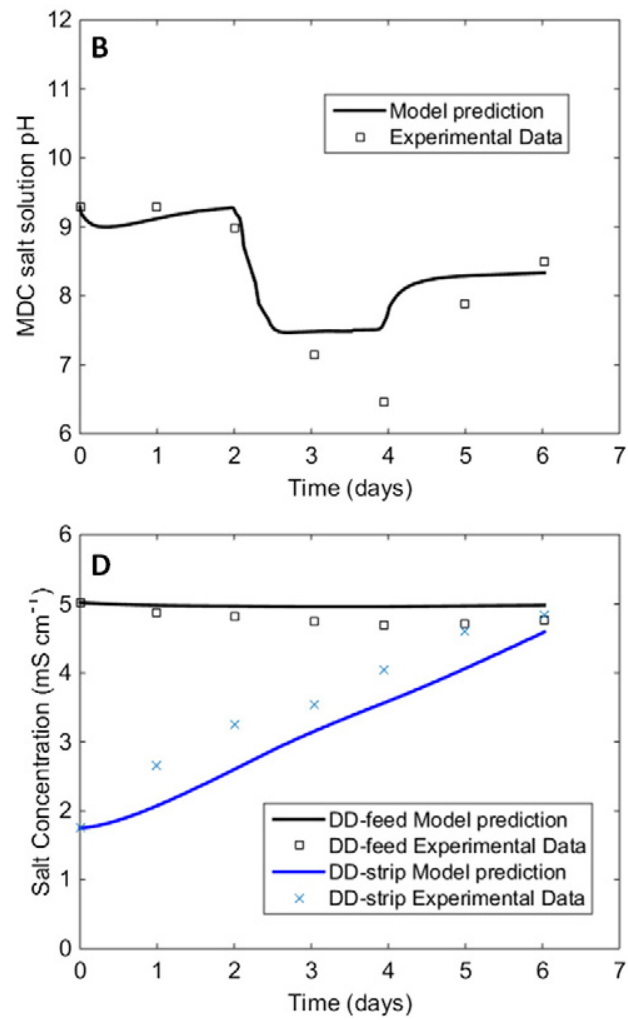

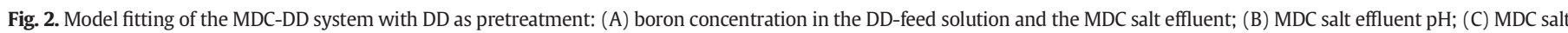
effluent conductivity; and (D) DD-feed and strip solution conductivity. 
boron concentration fitting decreased from $52.00 \%$ to $11.25 \%$ (Fig. S3C \& $D$ and Fig. S4B \& D).

After calibration, the variation of current generation, salinity and solute concentration in response to the salt solution flow rates in the three operations was fitted by the model with small discrepancy. For example, in the DD pretreatment system, the model accurately simulated the MDC boron concentration and salt solution $\mathrm{pH}$ variation trend (Fig. 2A \& B). It should be noted that the experimental measurement of the boron concentration can only be precise to integers, and thus even the modeled data deviated slightly from the experimental data, it was still considered a good fit. Slight overestimation of the salt concentration in the MDC salt solution was observed at days 4-6 when the MDC recovered from low current generation, which was regulated by salt solution HRT (longer HRT resulted in a lower salt concentration and greater internal resistance, and vice versa) (Fig. 2C). This discrepancy could be possibly caused by the fact that the MDC salt influent concentration (DD-feed salt concentration in Fig. 2D) was affected by slight variation in the prepared solution while the model assumed constant salt solution input. In Fig. 2D, underestimation of the salt concentration in the stripping solution was observed; however, the simulation agreed well with the trend of the experimental data. This discrepancy was probably caused by the inadequate mixing under the experimental conditions, while the model assumed complete mixing of the liquid. The rest of the model fitting results can be found in the Supporting information. The RMSE values between the experimental data and modeled results were mostly $<10 \%$, except the relative higher discrepancy for the salt concentration in the MDC up to $22.67 \%$ with the DD as post-treatment (Table S2). The high RMSE of the salt concentration was caused by the limitation of interpolation of the experimental data and the inadequate data points.

\subsubsection{The MFC system}

The mass balance of batch operation was formulated by eliminating the dilution term $D_{x}$ (related to flow rates) in the existing continuous operation model. Both pretreatment and post-treatment of seawater or brackish water were simulated. In the MFC system, previously determined $a_{o}$ fitted well under the open circuit condition where the $\mathrm{pH}$ of the catholyte was not raised and boron was not subject to electromigration or current-induced convection (data not shown). The parameter $a_{c}$ was then calibrated under the condition of close circuit with the optimization tool, where the boron removal was contributed by the four forces $M_{\text {borate,cathode, }} D_{B, \text { cathode }}$, Conv $v_{B, \text { cathode,current, and }}$

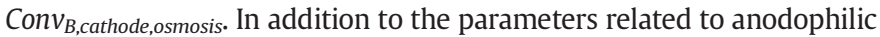
microorganism kinetics ( $Y$ and $x_{a}$ ), the alkali production efficiency $\left(a_{\mathrm{OH}}\right)$ and anion electromigration efficiency $\left(a_{e}\right)$ were also slightly adjusted during simulation.

The model results of current generation, catholyte salinity, $\mathrm{pH}$ and boron concentration generally followed the experimental data (Fig. 3), with some overestimation of the boron concentration (Fig. 3A and Figs. S6B \& S7B). The mismatch of the boron concentration in the first $0.4 \mathrm{~d}$ is probably due to the batch operation where the reactor might encounter an impulse response at the beginning and thus was not simulated by the model. The minimal removal of boron simulated by the model during pretreatment of seawater agreed with the experimental data with a small RMSE value of 5.62\% (Fig. 3D). The stable current generation in the MFC post-treatment of seawater system was fitted well by the model with RMSE of $6.1 \%$ (Fig. 3B). By adding the inhibition term in the microbial kinetics, which is governed by salt intrusion into the anolyte, the model can achieve satisfactory prediction of the declining current generation in the MFC pretreatment of seawater system (RMSE of 11.6\%) (Fig. 3E). The catholyte salt concentration under both post-treatment and pretreatment conditions was fitted well, although the model did not reflect the initial impulse response before $0.4 \mathrm{~d}$ in the batch operation (Fig. 3C \& F and Figs. S6D \& S7D). The RMSE values for the MFC system are shown in Table S3. As explained previously, the higher RMSE values of salt concentration could be caused by the limitation of interpolation.

\subsection{Model simulation}

\subsubsection{Boron removal in the MDC-DD system}

The model has simulated multiple outputs as a function of time. Both the DD-pretreatment and DD-post-treatment modes were simulated at two flow rates of the salt solution, 0.17 and $0.12 \mathrm{Ld}^{-1}$ (Figs. 4 \& S8). It is unlikely that the system will reach absolutely steady state, due to the recirculation between the MDC catholyte and the DD stripping solution that concentrates the salt in the system. Contradictory to our previous assumption that the accumulated anions in the DD stripping solution could outcompete the transport of hydroxide ions across the AEM and eventually diminish alkalization, leading to failure of boron removal,
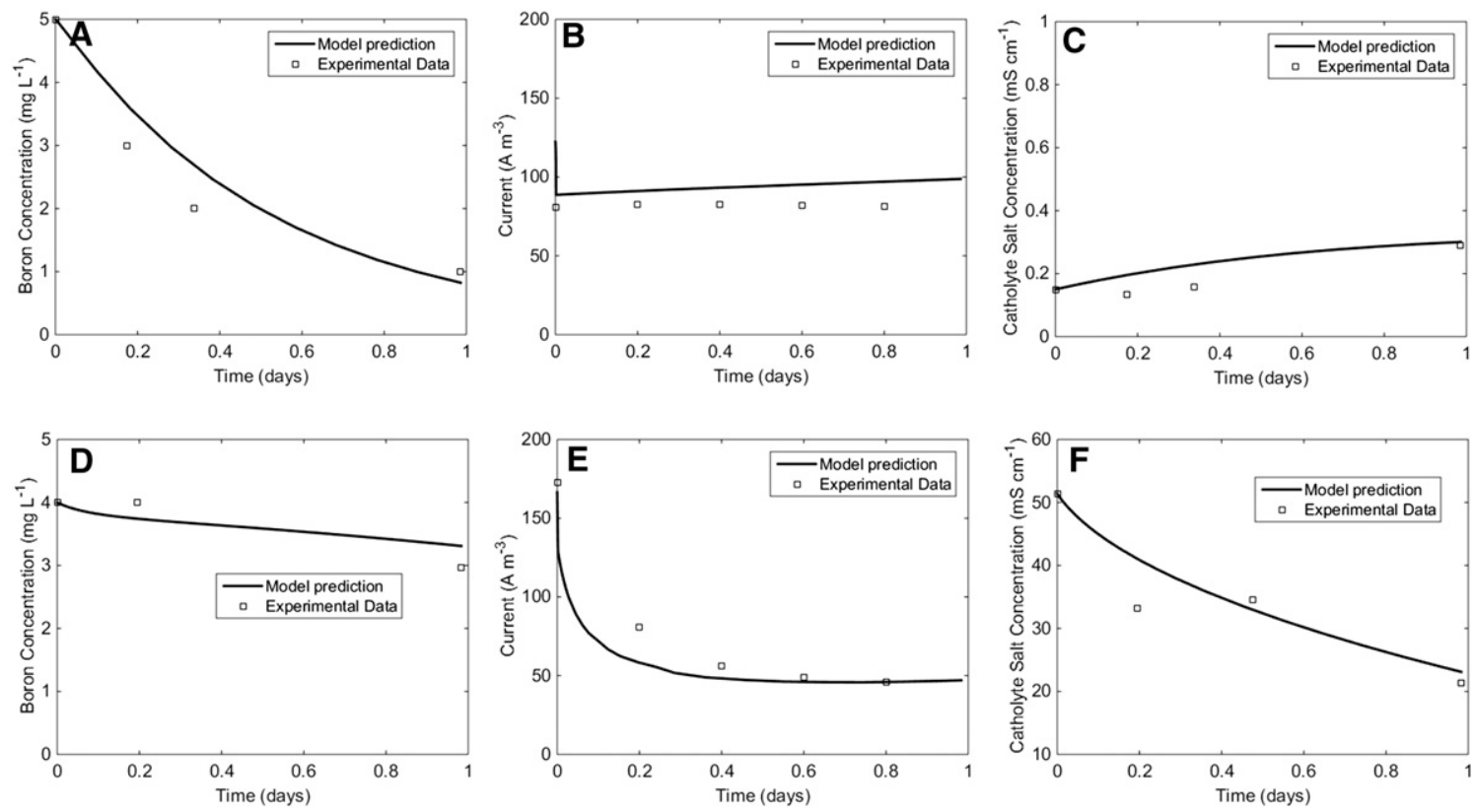

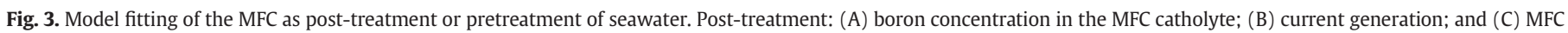
catholyte conductivity. Pretreatment: (D) boron concentration in the MFC catholyte; (E) current generation; and (F) MFC catholyte conductivity. 

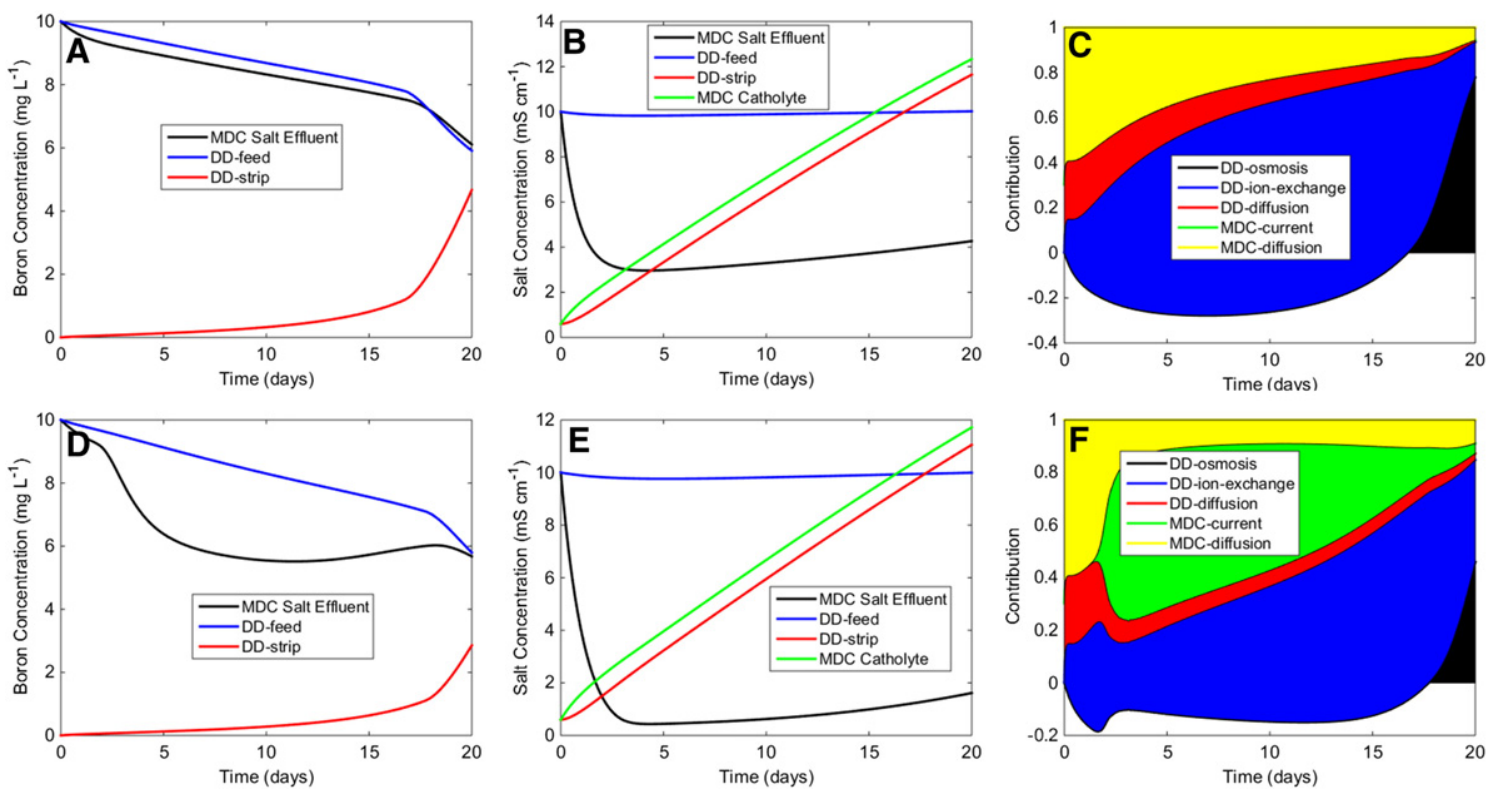

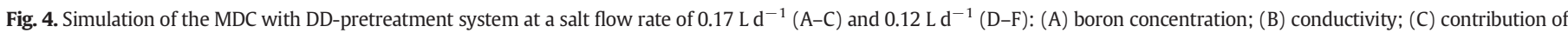
different driving forces to the boron removal; (D) boron concentration; (E) conductivity; and (F) contribution of different driving forces to the boron removal.

the simulated result indicates that the convective transport of boron owing to water osmosis from the feed into the stripping solution can effectively reduce boron concentration in the feed solution. In both the DD-pretreatment and DD-post-treatment modes, when the salt concentration in the stripping solution exceeds that of the feed solution around day 17 (Fig. 4A \& D) and day 5 (Fig. S8A \& D), a more rapid drop in boron concentration in DD-feed, and consequently more rapid increase of boron concentration in DD-strip are observed. Fig. 4C \& F and Fig. S8C \& F show the contribution of different driving forces, with the vertical span indicating the positive contribution to boron removal. It is observed that the contribution from osmosis-driven convective transport in the DD changes from negative to positive when the concentration difference reverses at day 17 in the DD-pretreatment system (Fig. 4B \& E) and at day 5 in the DD-post-treatment system (Fig. S8B \& E). The contribution by the DD-osmosis keeps increasing to $40-80 \%$ at day 20 in the DD-pretreatment system, and reaches $>90 \%$ in the DD-post-treatment system within 5 days. The early region where the contribution by the DD-ion-exchange (indicated by blue color) spans from negative to positive values suggests that the DD-osmosis driven boron transport (indicated by black color) has negative contribution and is offset by the DDion-exchange (Fig. 4C \& F and Fig.S8C \& F).

Current-driven transport of borate ions has very little influence on boron removal when the salt solution is operated at a flow rate of $0.17 \mathrm{~L} \mathrm{~d}^{-1}$ (Fig. 4C), while increasing the HRT by reducing the flow rate to $0.12 \mathrm{~L} \mathrm{~d}^{-1}$ enhances the current-driven removal of borate ions (indicated by green color) due to alleviated competition from other anions (Fig. 4F). In the MDC with DD-pretreatment system, although a faster flow rate of $0.17 \mathrm{~L} \mathrm{~d}^{-1}$ of salt solution in the MDC guarantees short HRT and maintains the $\mathrm{pH}$ above 10 (hydroxide ions are not removed in the desalination process) (Fig. S9A), borate ions have little chance to be removed from the solution due to the high concentrations of other anions (salt solution conductivity above $3 \mathrm{mS} \mathrm{cm}^{-1}$ (Fig. 4A)). Longer HRT (at a slower salt flow rate of $0.12 \mathrm{~L} \mathrm{~d}^{-1}$ ) can slightly improve boron removal in both pretreatment and post-treatment operations. The DD-post-treatment system is able to reduce boron concentration to around $1 \mathrm{mg} \mathrm{L}^{-1}$ at a salt flow rate of $0.12 \mathrm{~L} \mathrm{~d}^{-1}$ (Fig. S8D).

\subsubsection{Boron removal in the MFC system}

Unlike the MDC-DD system, the continuous operation of the MFC system can reach a steady state (e.g. MFC as post-treatment in Fig.
S10). Thus the simulation of the MFC system was performed for the steady state performance under varied conditions. The synergistic effects of catholyte flow rate, anolyte flow rate, as well as initial boron concentration on the boron removal in the catholyte and the boron accumulation in the anolyte were studied. In the MFC post-treatment system, the initial boron concentration is varied from 0 to $40 \mathrm{mg} \mathrm{L}^{-1}$ with the anolyte flow rate set at $1.44 \mathrm{~L} \mathrm{~d}^{-1}$ (Fig. $5 \mathrm{~A} \& \mathrm{~B}$ ). The simulation indicates that to achieve a boron concentration lower than $2 \mathrm{mg} \mathrm{L}^{-1}$, the catholyte flow rate needs to be regulated accordingly and requires a slower flow rate (thus a longer HRT) for higher initial boron concentration in the catholyte. For example, the initial $10 \mathrm{mg} \mathrm{L}^{-1} \mathrm{~B}$ solution will need the catholyte flow rate to be slower than $0.20 \mathrm{~L} \mathrm{~d}^{-1}$, while once the initial boron concentration drops below $5 \mathrm{mg} \mathrm{L}^{-1}$, the treating capacity can be extensively improved with the flow rate $>0.70 \mathrm{~L} \mathrm{~d}^{-1}$ (Fig. 5A). The resulted anolyte boron concentration in both cases is $<2 \mathrm{mg} \mathrm{L}^{-1}$ (Fig. 5B).

The effects of catholyte flow rate and anolyte flow rate were then studied under the condition of a high boron concentration of $40 \mathrm{mg} \mathrm{L}^{-1}$ (Fig. 5C \& D). The anolyte flow rate does not have much impact on the catholyte boron concentration unless it drops to an extreme low rate $\left(<0.10 \mathrm{~L} \mathrm{~d}^{-1}\right)$, which starves the anodophilic bacteria and stops current generation activity. The catholyte flow rate needs to be slower than $0.02 \mathrm{~L} \mathrm{~d}^{-1}$ to maintain a catholyte boron concentration lower than $2 \mathrm{mg} \mathrm{L}^{-1}$ (Fig. 5C). The boron concentration in the anolyte is controlled by both anolyte and catholyte flow rates. A higher catholyte flow rate brings in more boron and needs correspondingly a higher anolyte flow rate to dilute the boron concentration in the anolyte. The ratio between the anolyte flow rate and the catholyte flow rate should be $>22.2$ at the highest allowable catholyte flow rate of $0.02 \mathrm{~L} \mathrm{~d}^{-1}$ in order to achieve an anolyte boron concentration below $2 \mathrm{mg} \mathrm{L}^{-1}$. With a slower catholyte flow rate, this boundary ratio needs to further increase and vice versa (due to a complex effect by boron migration driving forces). For example, at $0.01 \mathrm{~L} \mathrm{~d}^{-1}$ catholyte flow rate, the ratio needs to reach 24.4 (Fig. 5D). It is also observed that the catholyte $\mathrm{pH}$ is kept above 9.7 in the simulation range, and a slower anolyte (catholyte) flow rate will decrease (increase) the $\mathrm{pH}$ due to reduced current generation (a longer HRT for hydroxide ion production) (Fig. S11).

Similar to the MDC-DD system, the osmosis-driven convection also plays an important role in the MFC system. In the MFC post-treatment system, at a catholyte flow rate of $0.02 \mathrm{~L} \mathrm{~d}^{-1}$ for treating $40 \mathrm{mg} \mathrm{L}^{-1} \mathrm{~B}$ 
A
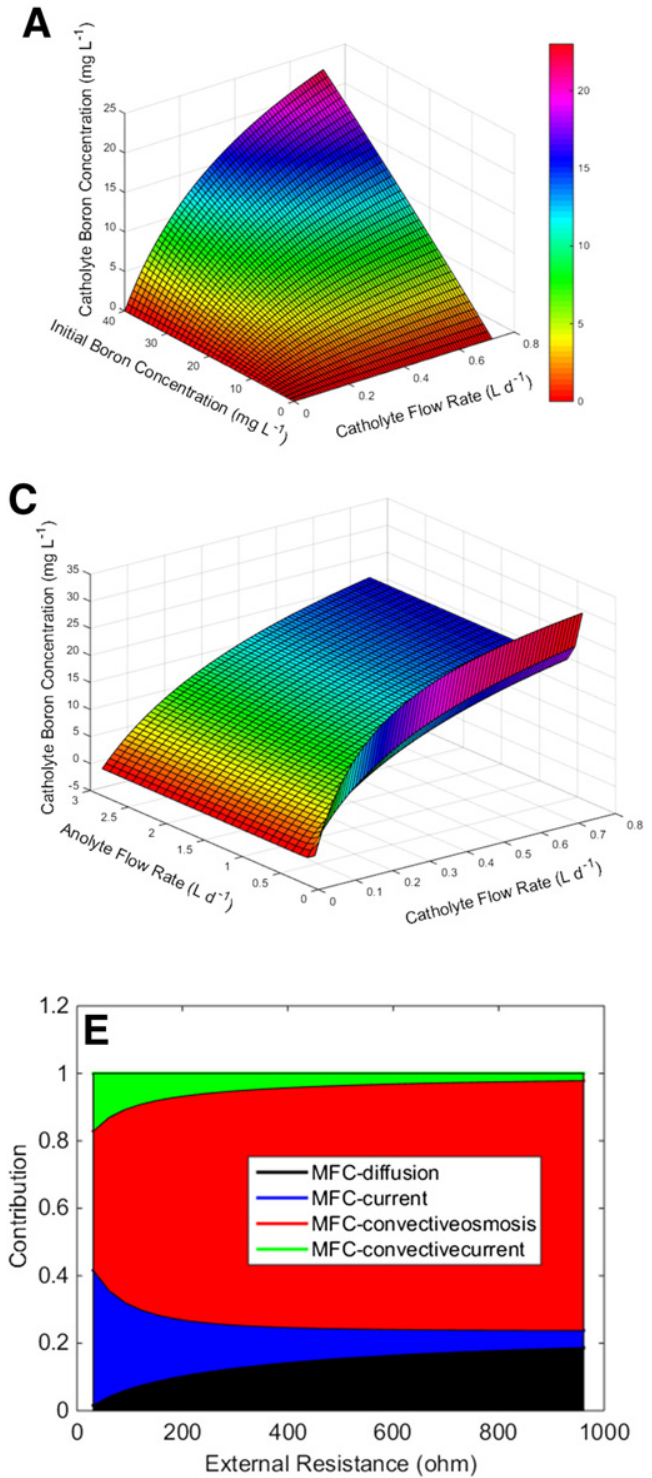

B

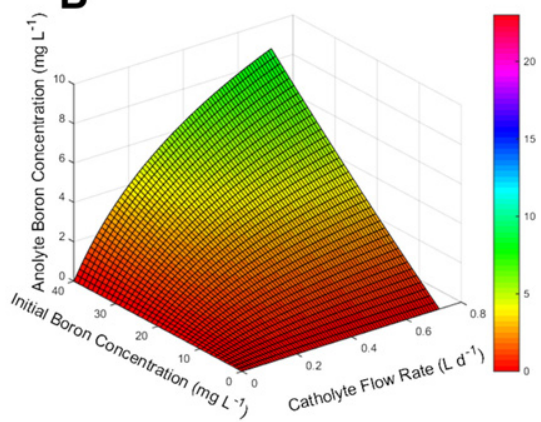

D
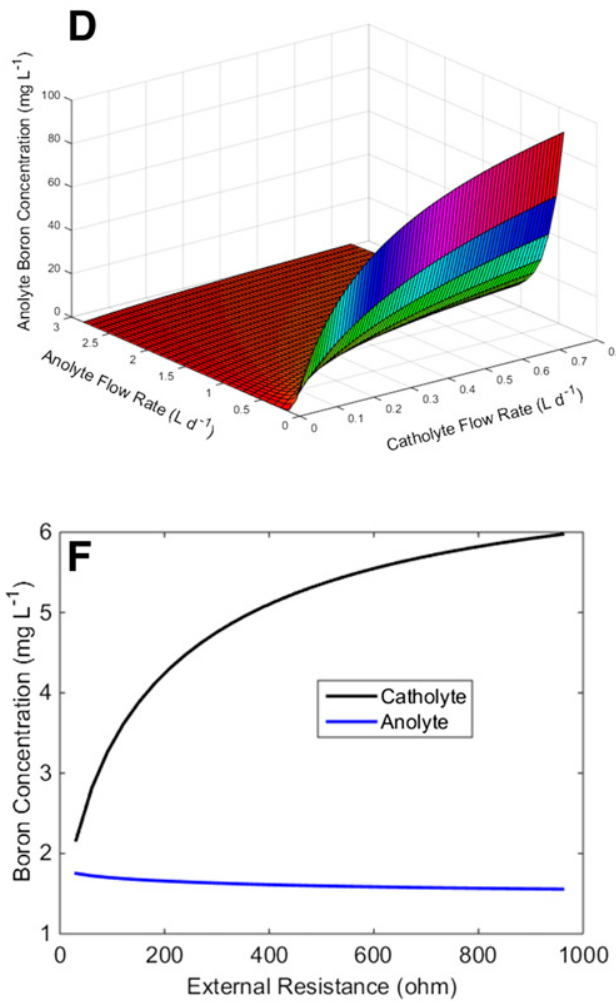

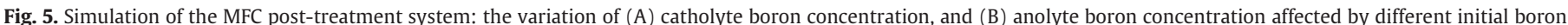

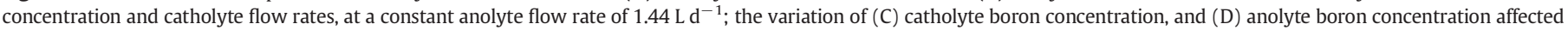

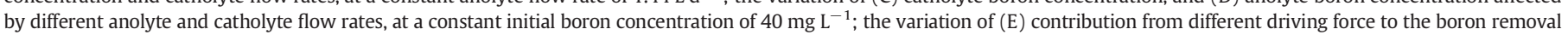
from catholyte, and (F) boron concentration in anolyte and catholyte affected by different external resistance. Color bar is inserted in A \& B for better comparison.

solution, almost $80 \%$ of the boron removal is attributed to the osmosisdriven convection under the condition of weak current generation (higher external resistance) (Fig. 5E). Lowering the external resistance to $30 \Omega$ will improve current-driven boron migration, and reduce the catholyte boron concentration to $<2.5 \mathrm{mg} \mathrm{L}^{-1}\left(\sim 6 \mathrm{mg} \mathrm{L}^{-1}\right.$ at $\left.900 \Omega\right)$ (Fig. 5F). This results in current-driven contribution of $40 \%$ to boron removal with another $40 \%$ contributed by osmosis-driven convection (Fig. $5 \mathrm{E}$ ). At an external resistance of $900 \Omega$, current-driven contribution is $<10 \%$.

In the case of the MFC as pretreatment of seawater (salt concentration of $35 \mathrm{~g} \mathrm{~L}^{-1}$ and boron concentration of $5 \mathrm{mg} \mathrm{L}^{-1}$ ), a unique issue is the inhibition of anodophilic bacteria due to transported salt from the catholyte. Thus the inhibition term $\frac{K_{I}}{K_{I}+\left(C_{\text {salt }, a}-C_{\text {salt }, a, 0}\right)}$ is simulated here with varied anolyte and catholyte flow rates. As expected, a faster anolyte flow rate ensures less inhibition of the bacteria, and the inhibition term can reach as close as to 1 (no inhibition effect). A faster catholyte flow rate has a negative impact on the inhibition, because it provides more salts being transported into the anolyte.
At a slower anolyte flow rate, the inhibition is more severe with increasing catholyte flow rate, due to the slow transport of salt out of the anolyte. To keep the inhibition term above $90 \%$, the catholyte flow rate needs to be below $0.02 \mathrm{~L} \mathrm{~d}^{-1}$, with the anolyte flow rate limit of $3 \mathrm{~L} \mathrm{~d}^{-1}$ (Fig. 6A). Both the catholyte boron concentration and salt concentration are reduced with a slower catholyte flow rate (longer HRT), but not affected by the anolyte flow rate until the anolyte flow rate slows down to $0.14 \mathrm{~L} \mathrm{~d}^{-1}$ and the accumulated salt in anolyte reaches a high level (Fig. 6B \& C \& D). For example, the anolyte salt concentration reaches $30.6 \mathrm{~g} \mathrm{~L}^{-1}$ at the anolyte and catholyte flow rates of 2.44 and $0.16 \mathrm{~L} \mathrm{~d}^{-1}$, respectively, while the catholyte salt concentrations is lower at $21.4 \mathrm{~g} \mathrm{~L}^{-1}$ (Fig. 6B \& D). At this stage the salt diffusion from the catholyte to the anolyte is diminished and it may even cause diffusion of salt in opposite direction. The anodophilic bacteria could be extremely inhibited. A sharp decrease of the catholyte boron concentration is observed due to the osmotic water flux induced boron transport from the catholyte into the anolyte. 

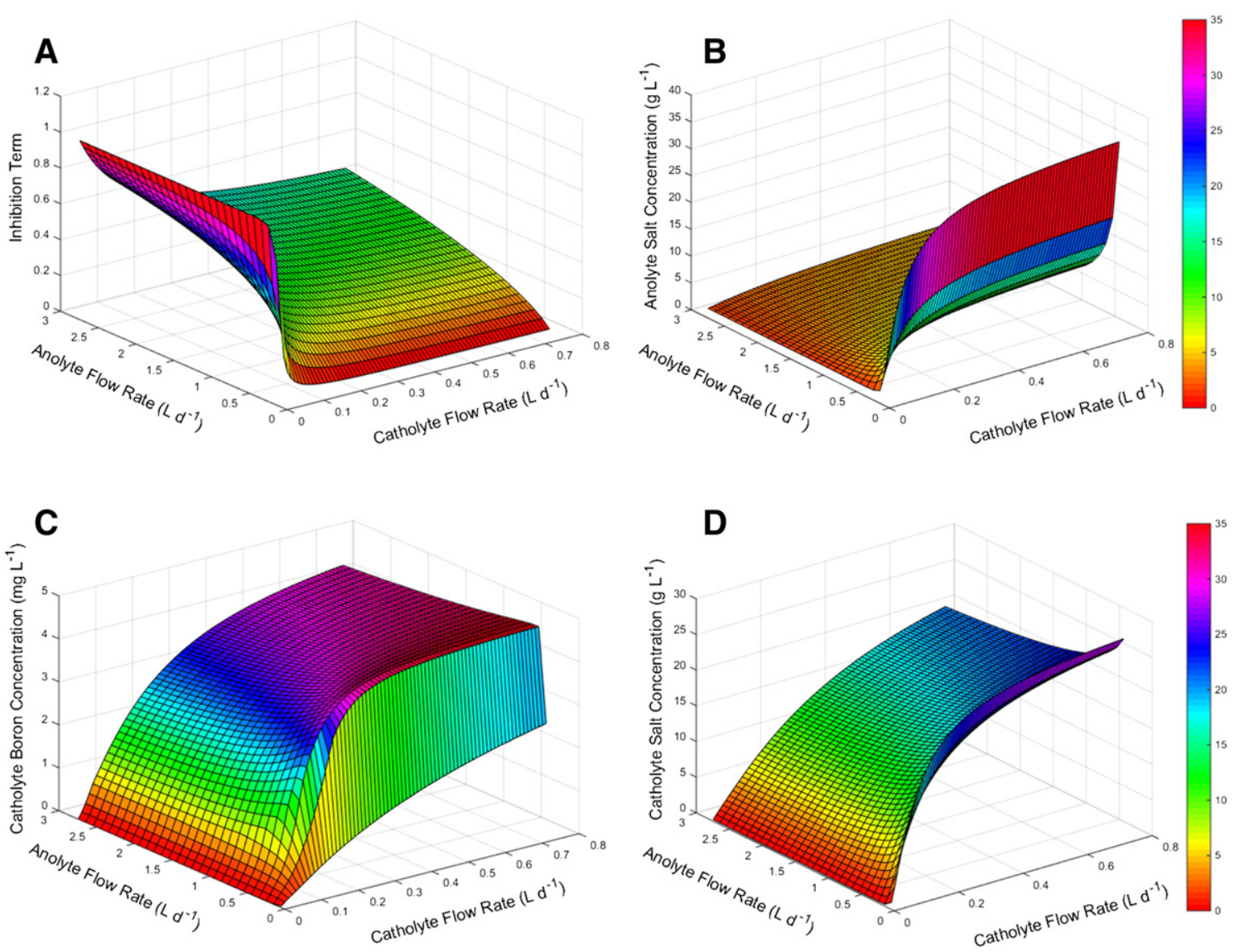

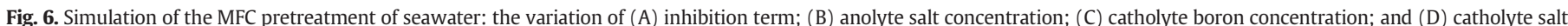

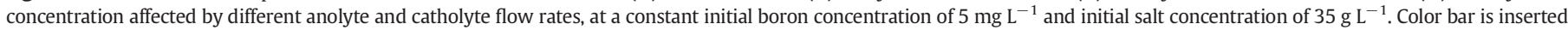
in B \& D for better comparison.

\section{Conclusions}

Mathematical modeling has been demonstrated as an effective tool to examine the mechanism of boron removal in BES. The driving forces of boron removal include electromigration induced by current generation and diffusion induced by concentration gradient. Convection transport induced by osmotic flux in the MFC and the DD plays a major role in boron removal. Additionally, current-induced convection in the MFC and ion-exchange in the DD also contribute to boron removal. The modeled results fit the experimental data well and provide valuable information for understanding long term performance. In the MDC-DD system, although the boron concentration in salt solution can be reduced to meet WHO regulation during a long-term operation, the system cannot reach steady state and has potential risk of unsatisfied salt concentration in the desalination effluent. The MFC can ensure effective boron removal, while the anolyte flow rate needs to be cautiously regulated in accordance to the catholyte flow rate as well as salt concentration to avoid severe inhibition to current generation. When the MFC catholyte has a high loading of salt, a short anolyte HRT is required to reduce the salt effects on the anode activity through dilution. Extending the HRT of the MFC catholyte can ensure a low boron concentration.

\section{Acknowledgments}

This work was made possible by NPRP grant \# 6-289-2-125 from the Qatar National Research Fund (a member of Qatar Foundation). The statements made herein are solely the responsibility of the authors.

\section{Appendix A. Supplementary data}

Supplementary data to this article can be found online at http://dx. doi.org/10.1016/j.scitotenv.2016.06.220.

\section{References}

Bennett, A., 2013. 50th anniversary: desalination: 50 years of progress. Filtr. Sep. 50 (3), $32-+$.

Cao, X., Huang, X., Liang, P., Xiao, K., Zhou, Y., Zhang, X., Logan, B., 2009. A new method for water desalination using microbial desalination cells. Environ. Sci. Technol. 43 (18), $7148-7152$.

Dydo, P., 2012. The mechanism of boric acid transport during an electrodialytic desalination process. J. Membr. Sci. 407, 202-210.

Dydo, P., Turek, M., 2013. Boron transport and removal using ion-exchange membranes: a critical review. Desalination 310, 2-8.

Grady, C.P.L., Daigger, G.T., Love, N.G., Filipe, C.D.M., 2011. Biological Wastewater Treatment. third ed. CRC Press, Boca Raton.

Gude, V.G., 2016. Desalination and sustainability - an appraisal and current perspective. Water Res. 89, 87-106.

Guler, E., Piekacz, J., Ozakdag, D., Kujawski, W., Arda, M., Yuksel, M., Kabay, N., 2009. Influence of the chosen process parameters on the efficiency of seawater desalination: SWRO pilot plant results at Urla Bay seashore. Desalin. Water Treat. 5 (1-3), 167-171.

Guler, E., Ozakdag, D., Arda, M., Yuksel, M., Kabay, N., 2010. Effect of temperature on seawater desalination-water quality analyses for desalinated seawater for its use as drinking and irrigation water. Environ. Geochem. Health 32 (4), 335-339.

Guler, E., Kaya, C., Kabay, N., Arda, M., 2015. Boron removal from seawater: state-of-theart review. Desalination 356, 85-93.

Harnisch, F., Warmbier, R., Schneider, R., Schroder, U., 2009. Modeling the ion transfer and polarization of ion exchange membranes in bioelectrochemical systems. Bioelectrochemistry 75 (2), 136-141.

Kabay, N., Bryjak, M., 2015. Boron Separation Processes. Elsevier, Amsterdam, pp. 219-235.

Li, W.W., Yu, H.Q., He, Z., 2014. Towards sustainable wastewater treatment by using microbial fuel cells-centered technologies. Energy Environ. Sci. 7 (3), 911-924.

Luo, S., Sun, H.Y., Ping, Q.Y., Jin, R., He, Z., 2016. A review of modeling bioelectrochemical systems: engineering and statistical aspects. Energies 9 (2). 
Melnik, L., Vysotskaja, O., Kornilovich, B., 1999. Boron behavior during desalination of sea and underground water by electrodialysis. Desalination 124 (1-3), 125-130.

Nikonenko, V.V., Pismenskaya, N.D., Belova, E.I., Sistat, P., Huguet, P., Pourcelly, G., Larchet, C., 2010. Intensive current transfer in membrane systems: modelling, mechanisms and application in electrodialysis. Adv. Colloid Interf. Sci. 160 (1-2), 101-123.

Picioreanu, C., van Loosdrecht, M.C.M., Curtis, T.P., Scott, K., 2010. Model based evaluation of the effect of $\mathrm{pH}$ and electrode geometry on microbial fuel cell performance. Bioelectrochemistry 78 (1), 8-24.

Ping, Q.Y., Zhang, C.Y., Chen, X.E., Zhang, B., Huang, Z.Y., He, Z., 2014. Mathematical model of dynamic behavior of microbial desalination cells for simultaneous wastewater treatment and water desalination. Environ. Sci. Technol. 48 (21), 13010-13019.

Ping, Q., Abu-Reesh, I.M., He, Z., 2015a. Boron removal from saline water by a microbial desalination cell integrated with Donnan dialysis. Desalination 376, 55-61.

Ping, Q.Y., Huang, Z.Y., Dosoretz, C., He, Z., 2015b. Integrated experimental investigation and mathematical modeling of brackish water desalination and wastewater treatment in microbial desalination cells. Water Res. 77, 13-23.

Ping, Q., Abu-Reesh, I.M., He, Z., 2016. Enhanced Boron Removal by Electricity Generation in a Microbial Fuel Cell (Submitted to Desalination).
Popat, S.C., Ki, D., Rittmann, B.E., Torres, C.I., 2012. Importance of OH-transport from cathodes in microbial fuel cells. ChemSusChem 5 (6), 1071-1079.

Qin, M., Ping, Q.Y., Lu, Y.B., Abu-Reesh, I.M., He, Z., 2015. Understanding electricity generation in osmotic microbial fuel cells through integrated experimental investigation and mathematical modeling. Bioresour. Technol. 195, 194-201.

Sevda, S., Yuan, H., He, Z., Abu-Reesh, I.M., 2015. Microbial desalination cells as a versatile technology: functions, optimization and prospective. Desalination 371, 9-17.

USBR (U.S. Bureau of Reclamation), 2003. Desalting Handbook for Planners. third ed. USBR, Washington, D.C.

Venkidusamy, K., Megharaj, M., Marzorati, M., Lockington, R., Naidu, R., 2016. Enhanced removal of petroleum hydrocarbons using a bioelectrochemical remediation system with pre-cultured anodes. Sci. Total Environ. 539, 61-69.

Wang, H., Ren, Z.J., 2013. A comprehensive review of microbial electrochemical systems as a platform technology. Biotechnol. Adv. 31 (8), 1796-1807. 